\title{
UMA CARTOGRAFIA SUBMERSA PARA PENSAR A PRODUÇÃO DO CORPO INTENSIVO
}

\author{
Fernando Yonezawa \\ Universidade Federal do Espirito Santo, Vitória, Espirito Santo, Brasil \\ Luciana Caliman \\ Universidade Federal do Espirito Santo, Vitória, Espirito Santo, Brasil
}

\begin{abstract}
Resumo
Este trabalho pretende apresentar uma cartografia da prática do mergulho livre e, com base na concepção de corpo sem órgãos das obras de Deleuze e Guattari, extrair elementos que possibilitem refletir sobre a produção de um corpo intensivo, distinto do corpo orgânico. Partimos da noção de que o corpo sem órgãos seja o corpo dos afectos circulantes em um encontro entre corpos. Pretendemos contribuir para as reflexões acerca do corpo, realizando uma listagem de afectos da prática do mergulho livre no mar e elaborando a noção de que um corpo intensivo é construído a partir de experimentações capazes de constituir novos campos de sensibilidade.
\end{abstract}

Palavras-chave: Cartografia. Mergulho. Corpo. Sensibilidade.

\section{Corpo sem órgãos, campos de sensibilidade e cartografia}

Objetivamos, aqui, cartografar a prática corporal do mergulho livre e, apoiados no conceito de corpo sem órgãos, compreender a concepção de corpo intensivo e a respectiva produção de campos de sensibilidade.

Para tanto, tomaremos a atividade do mergulho livre como "ação livre". Segundo Deleuze e Guattari (1997b, p.76), na ação livre, diferentemente do que ocorre no trabalho, o movimento contínuo "não tem resistência a vencer, só opera sobre o próprio corpo móvel, não se consome no seu efeito" e, além disso, nela, "o que conta é a maneira pela qual os elementos do corpo escapam à gravitação" para ocupar um espaço não pontuado.

Passemos, assim, para o conceito de corpo sem órgãos (CsO). Como dizem com mais precisão Deleuze e Guattari (1996, p.9), o CsO "não é uma noção, um conceito, mas antes uma prática, um conjunto de práticas". Ainda nas palavras dos autores, "o CsO é a substância imanente" e é também "a matéria que preenche sempre o espaço com este ou aquele grau de intensidade [...]" (DELEUZE; GUATTARI, 2010, p. 432) O CsO se produz como corpo de uma ação livre. Isso quer dizer que o CsO é produto de um encontro sem meta a cumprir; encontro tomado do ponto de vista dos afectos produzidos, isto é, das intensidades, e não da extensividade, a qual envolveria os dados designáveis referenciados a uma fisiologia e anatomia preestabelecidas.

Deleuze e Guattari denunciam a ineficácia do organismo para dar conta da intensidade do $\mathrm{CsO}$. O limite do organismo está em ser apenas uma representação do corpo, um tipo de esquadrinhamento predeterminado de seus fluxos e potências. Foucault (2000, p.196) descre- 
ve todo o agenciamento social e político que envolveu a consolidação da medicina como formação de poder que detém saber privilegiado sobre o corpo. Ele mostra como foi preciso saquear corpos dos cemitérios, invadir casas, disputar poder com religiosos e curandeiros, para fazer do corpo um organismo. O organismo é, pois, o corpo imantado ao controle estatal através do discurso da saúde perfeita promulgado pela medicina. Certamente, o corpo é aquilo sobre o qual o organismo se impõe, mas ele não se limita a isso que se lhe impõe: sempre há uma multiplicidade desconhecida de que o corpo é capaz. O CsO não é, porém, um corpo subjetivo das vivências de um 'eu', corpo de sentimentos hegemônicos, já significados. O CsO é corpo de afectos não instituídos socialmente, por isso, causa tensões ruinosas ao organismo. Orlandi (2004, p.78) precisa que o CsO é uma "imantação de linhas de fuga", ou seja, é graças a ele que nosso corpo é mais do que um 'eu' e um organismo: é ele que nos dá sempre um excedente vivo de afectos. Segundo Deleuze e Guattari (1996, p.13), "ele é matéria intensa e não formada [...], matriz intensiva". "Ovo intenso que se define por eixos e vetores, gradientes e limiares, tendências dinâmicas com mutação de energia." Ele é adjacente ao organismo, não anterior a ele; é embrião que, ao lado do organismo (imanente), está sempre a se proliferar. Ora, os afectos se distinguem dos afetos-sentimentos, embora os envolvam. (DELEUZE, 2002, p.56) Os afectos, sendo intensivos, não têm a forma designativa dos afetos, isto é, eles não constituem estados emocionais estabelecidos; são linhas de sensibilidade que correm entre os estados formais, nos dando o sentido de passagem para uma modulação desconhecida, um devir. Logo, a ampliação de afectos resulta sempre em ampliação dos afetos possíveis.

O CsO é um corpo no qual estados paradoxais trazem todo o sofrimento da dissolução egoica, mas também a alegria de um corpo estrangeiro aos modos de vida demasiado institucionalizados. Neste sentido, a experimentação é a própria prática política que se arrisca a produzir uma vida singular. Se o organismo é o roubo do corpo, a fabricação experimental de um $\mathrm{CsO}$ é a retomada do corpo através do encontro com suas potências.

Assim, a experimentação se faz numa relação entre corpos que tem duas frentes de guerrilha: uma quer destituir os poderes do organismo, a outra cria afectos insuspeitos, capazes de dar ao corpo o estatuto de fábrica inventiva. De um lado, despoluir o corpo da moral médica que o força a ser são ou doente: corpo capturável pelo Estado, pelo trabalho, pelos saberes prefabricados; de outro, constituir uma via de criação de novos corpos, portadores de novos afectos, nova sensibilidade.

A experimentação é, pois, feita em nome da produção de uma nova forma de fortitude: aquilo que Artaud (2006, p.151) chamou de "atletismo afetivo" e que vem do "desenvolvimento de uma musculatura afetiva". Desta forma, cada CsO precisa ser tomado do ponto de vista do tipo de experiência intensiva que produz, de quais procedimentos o fabricam, o que ele faz circular e quais surpresas ou impasses traz (DELEUZE e GUATTARI, 1996, p.12). Então, a partir deste outro corpo construído, é preciso encontrar uma maneira de acompanhar seus fluxos.

Acreditamos, pois, que toda investigação ou prática é uma forma de viagem. Como tal, precisa recorrer a uma estratégia de navegação. Aqui, tomaremos como estratégia de navegação a cartografia. Ora, em sua viagem, o cartógrafo precisa ser sensível às ondulações da realidade, atentando-se também àquilo em que ele próprio se transforma no trajeto. A essa disposição, Alvarez e Passos (2010, p.137) chamam "receptividade afetiva". Desenvolver uma sensibilidade, eis o elemento cartográfico. Por isso, se diz que o objeto de investigação na cartografia poderia ser visto como "expressão possível das sensações, percepções e afectos do cartógrafo" (KIRST, 2003, p.97). Também Deleuze (1997, p.77) diz da cartografia como um mapa ou listagem de afectos. A cartografia é, assim, a produção de uma sensibilidade à metamorfose que chega num trajeto realizado. "O mapa exprime a identidade entre o percurso e o percorrido" (DELEUZE, 1997, p.73) 
Cartografar é, pois, desposar o presente em mutação. O cartógrafo faz do recomeço e do não saber o seu tempo. "O que carece de forma penetra o impenetrável" (TSÉ, 2000, p.105). E o impenetrável é justamente o devir, que só pode ser captado por uma sensibilidade fina, por uma sabedoria que desconhece. Porém, cartografar não é lançar-se num vazio exasperado. Segundo Amador e Fonseca (2009, p.34), trata-se de criar "zonas de duração", as quais funcionam como "centros de estabilidade momentânea", como são os recifes de coral no meio do oceano, que aglomeram caudais de seres sobre um plano de equilíbrio frágil. Ora, o trabalho cartográfico investiga o real não enquanto plano empírico, mas como plano povoado de afectos, no qual se faz o "acompanhamento de processos" (ALVAREZ e PASSOS, 2010, p.135). Ora, é tarefa da cartografia captar os novos materiais afectivos tecidos sobre um CsO.

Compreendidos os conceitos que nos embasam, partiremos agora para a listagem de afectos implicada na prática do mergulho livre.

\section{Mergulhar: a-fundar em outro mundo}

Chama-se mergulho livre aquele que é realizado, seja em mar, seja em água doce, apenas com o ar do peito, máscara, nadadeiras e snorkel, sem tanque de oxigênio, que permita estar submerso por muitos minutos. Aqui privilegiaremos a experiência do mergulho em mar.

O snorkel e as nadadeiras são dispensáveis, pois muitas vezes o mais interessante na água não se encontra na superfície, e as nadadeiras podem ser desconfortáveis por esbarrarem facilmente no fundo arenoso da água, revolvendo-o e turvando a visibilidade. Assim, o mergulho livre é necessariamente um mergulho descarregado: vamos apenas com o que permite ver a beleza do mar e com a capacidade de nadar submerso. Mergulho feito com a força que temos no peito. É assim que gostamos de praticá-lo; é leve, alonga e cria espaços no peito, no sentido físico e afetivo.

Logo, para mergulhar no mar, é preciso saber nadar bem: não estaremos onde possamos nos manter bípedes, seguros de nossa posição de supostos cumes da escala evolutiva. Estaremos à deriva, com o corpo menos aterrado pela gravidade e totalmente exposto às fluências da água tão ignorante do bem ou mal. Saber nadar é necessário porque possibilita conduzir-se na água, usufruindo de suas carícias. Nadar bem possibilita, não nos deixa perigosamente passivos na água. É nadando que podemos ser passados pelo que se passa no mar, pela sua vida.

No entanto, nadar bem não é suficiente para mergulhar. Aquilo que se aprende na escola de natação, numa água laboratorial, desprovida de ondas, correntes e ventos, é apenas técnica para ir adiante na água. Aprender a nadar não é ainda mergulhar e tornar o corpo parte do mar. Mergulhamos para ficar imersos, abraçados pelo mar e surpreendidos pela sua estranheza, suas formas de vida 'alienígenas', algumas moles, gelatinosas, outras perfurantes e cortantes. Com efeito, estamos lá dentro para sermos esteticamente alimentados e para respeitarmos a força não intencional, mas poderosa, da água.

Mergulhar performatiza uma relação com o mar diferente desta familial e turística, em que se vai à praia para pular ondas, beber caipirinha e deixar o corpo bronzeado para exibir às amigas. Também não é outra relação clichê, que reproduz na praia um ambiente de festa em boate noturna, reatualizando, agora com os corpos seminus, o clima de cio das diversões urbanas. Mergulhar é saborear outra estética, não é ir consumir a praia e as silhuetas corporais próximas das midiáticas; não é, sobretudo, poluir o mar e fazer dele mais um local de desforra da vida servil de trabalhador. Se se consome algo, é a estética da natureza, para se embriagar de outro modo, sem poluir a água com a embriaguez da alegria enlatada e com copos e corpos de plástico. Ao mergulharmos, aprendemos a desejar que o mar esteja despoluído, livre da bebedeira tão afeita à ordem do dia dos economicamente ativos, sedenta por vingar-se das centenas de dias afogados em trabalho. Além disso, no mergulho livre, estamos descolados da 
necessidade de tirar do mar o alimento diário. Na produção do $\mathrm{CsO}$ do mergulho, desterritorializamos estas linhas que também constituem o organismo.

Estar imerso é estar em um mundo desconhecido, onde nos movemos mal e o mais fácil é morrer. Mas encontramos aí um bonito paradoxo (toda beleza tem seu perigoso paradoxo): mergulhar é a-fundar, é habitar por alguns instantes uma vida sem fundamento, sem a segurança do chão e de nossas certezas; mesmo assim, estar afundado é estar envolvido, abraçado pela água. Porém, o abraço é selvagem: certas águas são muito geladas, por conta das correntes marinhas que as constituem. Logo que se entra nelas, a boca protesta por causa do sal, permanecer por mais de meia hora já faz os lábios ficarem com gosto de ferro e a garganta arde quando engolimos água acidentalmente.

Por outro lado, há um cheiro próprio do mar. O cheiro do mar espalha pela pele das costas uma sensação morna e amarelada. Uma umidade salgada com aroma de algas vai acariciando as mucosas. O sabor da água do mar é uma mistura de sol e verde. E, aí, o inicial desconforto já passou, tornou-se experiência estética, poética: são as primeiras linhas de intensidade que nos chegam. Há espuma acariciando os ouvidos com um borbulhar pequenino, com dedos pueris. A pele, que estava arrepiada com a diferença de temperatura, já sente tudo como frescor. A água fria deslizando no corpo traz a sensação de que não temos órgãos internos, apenas uma pele lisa, fluida e prateada, que cintila pontos de luz estelar: talvez não seja à toa que muitos peixes tenham seu couro prateado e brilhante. O corpo então já está leve, a cabeça está fora, mas os braços e pernas vistos abaixo da água são nebulosos, ondulantes, de contornos borrados: a nitidez das linhas do corpo se liquefaz, inicia-se a desconstrução do corpo individual.

Nadamos para perto das pedras, onde haja águas sem ondas agitadas e que tenham profundidade. É preciso evitar os ventos, que fazem a água agitar-se e turvar-se. Então, apertamos a máscara contra o rosto para garantir boa vedação, pois arde muito se a água salgada invade o nariz. Isso justifica a cobertura do nariz que a máscara oferece: embaixo, onde a pressão aumenta, a água é capaz de entrar pelas narinas. Agora com a água até o pescoço, há um pequeno esforço para flutuar; ondulamos levemente as pernas e mãos. Respiramos mais ofegantes, sentimos poder afundar fatalmente. $\mathrm{O}$ verde da água está logo abaixo do queixo, o cheiro de algas também, muito mais próximo. Olhamos em volta, tudo é verde, brilho de sol prateando a água trêmula; há brilhos que até ofuscam os olhos. O contorno do corpo é uma sensação fresca, homogênea, sem lacunas. Estar parado é ilusão, o mar carrega imperceptivelmente, com periclitante doçura. O céu parece maior, mais pesado, uma abóboda azul larga e alta.

Nadamos um pouco na superfície, já com a cabeça na água, com a respiração presa. Enquanto aquecemos o exercício de apneia, estamos procurando alguma beleza ou esquisitice que nos chame a descer mais fundo. Levantamos a cabeça, respiramos um pouco, recuperamos o fôlego. Novamente nadamos, procuramos, deixamos o corpo lidar com a flutuação. Uma leve contração nas costas, para manter os membros esticados e o corpo espalmado na superfície. Colocamos a cabeça na água apenas até a altura dos olhos e admiramos a fina película ondulante que divide dois mundos. Vemos simultaneamente o mundo em que pisamos e o mundo marinho, o céu azul acima e a divisão luminosa que a água faz para marcar onde começa sua Atlântida.

Então, os pulmões esticam numa inspiração grande com boca e nariz. Mesmo que não vejamos nada especial, é hora de afundar deliberadamente: a profundidade chama, seduz em silêncio. Dobramos o corpo e fazemos um esforço com braços e pernas para descer. O mundo humano aquieta, não há mais vozes, a não ser a das bolhas, do pouco de ar que é preciso soltar para descer (os pulmões muito cheios nos fazem flutuar). Já descemos dois metros, as bolhas param, ouve-se um fluxo de pequeninos estalos, que não é possível saber do que se trata. Sentimos um frio na barriga também. Há uma emoção estranha, o terror encantador de estar dian- 
te de um mundo gigantesco, desconhecido. Descendo mais, já se está facilmente a mais de três metros. Perto das pedras sempre há muita vida, muita delicadeza e muitas lâminas perigosas das diversas espécies de conchas. A pele cortada por conchas dói mais do que quando ferida por objetos terrenos; são ferimentos que demoram mais para cicatrizar também: de fato, ali somos nós os forasteiros. Vê-se muitos ouriços dentro de suas pequenas crateras nas pedras, corais arroxeados, esponjas de um laranja enferrujado, caranguejos grandes da cor do crepúsculo entocados em fendas, conchinhas espiraladas que às vezes abrigam moluscos e outras vezes já se tornaram lar de um caranguejo ermitão. As pedras têm pele, são quase que inteiramente cobertas de vida, seres que nunca sabemos bem se são animais ou vegetais, flores ou espinhos; situam-se na passagem de reinos da natureza, vidas que dilatam e contraem, refugiam-se muito velozmente para dentro de uma pequena casca ao mínimo toque.

Muito da vida marinha é pulsátil. Chegar perto destas criaturas é descobrir a poesia que há em pequeninas vidas sem consciência, apenas sensíveis, cujo toque se dá por tentáculos e bainhas ligadas a um único orifício, que serve de boca, de ânus, de canal de semeadura e pulverização de milhares de simulacros. São vidinhas floridas, que luzem roxos e azuis quando a água está cristalina e a luz do sol atravessa seus tentáculos gelatinosos. São milhares de existências intrigantes; perguntamos se são venenosas, se podemos tocá-las sem nos queimar. São minúsculas cavernas, pequeninos vulcões, de onde emergem fios e tentáculos. De repente, avistamos, no meio das cores escuras das pedras, entre algumas algas e alguns corais, uma estrela-do-mar. Está como estrelas do céu, numa paralisia aparente, numa mobilidade cuja velocidade escapa muito sofrivelmente do zero. Sua forma surpreende, pois não é como a dos livros escolares de biologia. Muitas estrelas aparecem dentro de um estreito vão entre as pedras, com os braços dobrados. Pegamos para ver a parte de seu corpo que está virada para a pedra: novamente, centenas de minúsculos tentáculos, que se movem como se cada um fosse um outro serzinho. Grudam nos nossos dedos, apalpam num caminhar que suga ponto a ponto. A estrela se afeta e ensina que é possível ter uma vida sensível sem a pesada aparelhagem da consciência. Quase esquecemos que estamos sem ar.

No mar, toda sensação é confusa. As estrelas-do-mar parecem macias, mas têm erupções duras sobre sua pele. Os olhos vão ao toque certos da maciez, os dedos descobrem o engano, mas também captam um aveludado, que é a da cor vermelho-camurça, das linhas arredondadas e do caminhar miudinho, que desfruta de um tempo viscoso. Encontramos também outro tempo quando, num dia com água aquecida pelo sol, vemos uma carambola-do-mar perto da superfície: ela pulsa gentil e despreocupada, impondo seu nado muito tenuemente, usando as coloridas e cintilantes fileiras de minúsculos cílios que percorrem seu corpo ovalado. Transparentes, nos aparecem como evanescentes brumas gelatinosas, pequeninos fantasmas com filetes de arco-íris.

Num mergulho, se ficamos conectados ao espaço marinho, com olhos atentos, mas sem medo, é possível ter a alma pintada pela visão de um peixe-trombeta, ou uma lula que, ao ser vista, também nos encara com grandes olhos e inicia uma ondulante mudança de cores a lhe salpicar o corpo. Quando encaramos a lula e ela nos encara, transformamo-nos temporariamente também num corpo leve e suspenso, silencioso e paralisado, na intenção de prolongar ao máximo o encontro com um ser que, sendo selvagem, facilmente se assusta e foge; cria-se uma duração microvibrátil, que admira e lentifica para poder manter um encontro de olhares que é, ao mesmo tempo, tenso e doce. A lula muda de cor, tenta crescer e silenciosamente se fazer indócil apenas com seus inúmeros pontinhos de pigmento cutâneo, enquanto nós tentamos parecer inofensivos. O interior do nosso corpo também se torna pele ou superfície aquática, tecido esticado e atravessado de vibrações, seda sensível à fragilidade deste encontro. Lá embaixo, o peso do corpo perde a gravidade e, no entanto, é difícil se mover. Já não há o organismo do homem branco, dominador e explorador: os órgãos do corpo aí estão substituídos por linhas de afectos do fundo do mar. O corpo se dilui, passa a vibrar segundo uma modula- 
ção afetiva distinta da forma terrena, mas também não chegando a estabelecer-se como vida aquática: estamos agora "na borda do vilarejo, ou entre dois vilarejos" (DELEUZE; GUATTARI, 1997a, p.28), estamos em devir.

Para isso tudo, saber nadar é importante, mas há muito mais estranhezas no mar do que a simples ignorância da técnica do nado. Se entramos numa água mais turva e muito profunda, ou se há enormes pedras, com muitas reentrâncias, logo nos vêm uma dupla sensação: há distâncias que a profundidade, a nebulosidade e as fendas ocultam e essas cavidades que percebemos empiricamente, ao mesmo tempo que são belas, escondem seres afectivos fanstamagóricos; ataques de criaturas ferozes e gigantes imediatamente nos tomam, trazendo toda a nossa vulnerabilidade à tona, fazendo-nos imergir também no enegrecido mar de bestas que nos constitui. Descobrimos que nosso corpo também tem mares e neles há grutas e fendas onde vivem quimeras, cuja precipitação depende de serem inundadas pelo mar exterior. Sente-se um medo do profundo, das coisas que se esquivam à luz, que só aparecem sendo dilaceradoras. Com este repentino pavor no corpo, a leveza foge, o ar acaba, o peito gela. O medo pesa, faz afundar. Contudo, o medo é também um chamado, uma forma de sedução, que as lendas sobre sereias explicam e as histórias das primeiras grandes navegações positivam.

No mar, as percepções dos órgãos dos sentidos escorregam uma sobre as outras, criando faixas em que elas se indeterminam; a água faz toda sensação ser também líquida: azuis são também transparentes, sem deixarem de ser gelatinosos. Por isso, os afetos são atraídos para zonas cheias de desconhecidos. A mestiçagem de sensações produz vacúolos escuros, de onde saem seres tão marinhos quanto os que vemos diante de nossos olhos. A estética da vida que nos passa no mergulho é uma mistura de barroco, impressionismo e surrealismo. O corpo é, ali, uma espécie de tela pintada de afectos que são cada vez menos sentimentos de um humano, para se tornarem o próprio CsO marinho. "Os afectos são devires" (DELEUZE; GUATTARI, 1997a, p.42). Nesta performance, não é o corpo do mergulhador que produz linhas intensivas, mas é a dupla relação de desterritorialização-singularização que, no experimento estabelecido com os corpos do mar, dá gênese a um transbordamento estético.

$\mathrm{O}$ ar acabou, começamos a subir com sentimento de urgência, mas tomando o cuidado para que não sejamos mais velozes do que as bolhas que soltamos, pois a despressurização muito rápida é danosa. Emergimos ofegantes. Respiramos algumas vezes para acalmar o corpo, inspiramos fundo novamente e imergimos. Novamente, os ventos de medo nos vêm, mas esta última respirada foi literalmente uma inspiração, para encher o peito também de coragem. Descemos velozmente, com uma braçada forte para mais fundo: cinco ou seis metros. Neste trajeto, os ouvidos começam a doer, por causa da pressão da água: facilmente resolvemos, apertando o nariz e expulsando a pressão com um assopro que sai pelos ouvidos. E aí, mais fundo, começam a aparecer cardumes, fluxos de peixes prateados. Eles aparecem do verde opaco da água como as figuras das pinturas barrocas, que se elevam da escuridão. No fundo arenoso, pode-se descobrir uma arraia: nada como se fosse um grande lenço. Embaixo das pedras, encontramos pequenos peixes coloridos de amarelos, azuis, violetas, vermelhos tão intensos, que parecem pintados nas nossas tecnológicas telas de alta definição. Mas não, "a arte não é privilégio do homem" (Deleuze; Guattari, 1997a, p.123) e lá, mergulhados, percebemos que a natureza é a mais esquizofrênica e primeira das artistas.

Algumas vezes, quando descemos em regiões um pouco mais afastadas das pedras e olhamos em volta, tudo é vazio e transparente, só há areia abaixo e sente-se uma solidão aterradora, o mais perfeito sentido de abandono. Nestas regiões, nota-se todo o espaço vazio que tem o mar. Sente-se uma liberdade abissal, assustadora. Olhamos para cima, o ar está acabando mais uma vez... a película da água lá em cima forma um espelho que não reflete. Uma das mais belas visões do mergulho é ver de baixo a luz refletida na superfície da água, alguns raios do sol entrando, o céu ondulando lá em cima; cria-se nova ilusão: sentimos com a pele do corpo a água nos envolvendo de verde molhado, mas vemos uma superfície lá em cima que dá 
a sensação de que tudo em torno é vazio. Subimos calmamente para aliviar a pressão aos poucos, mas com os pulmões desesperados por ar. Voltamos em meio às nossas próprias bolhas.

Mais algumas respiradas com a cabeça fora e, de novo, uma inspiração corajosa. Deslizando perto do fundo, um peixe falso voador se assusta, abre suas asas de contornos e pintas cor azul néon e escapa com seu belo leque luminoso. Contemos o fôlego um pouco mais. $\mathrm{O}$ olhar longevo e sereno de uma tartaruga nos surpreende, mas ela também foge com agilidade. Ficar embaixo, ver o brilho da superfície, tentar aguentar um pouco mais, são as emoções cíclicas do mergulho. Subir para recomeçar, não saber o que encontrar, poder recolocar a possibilidade de encantarmo-nos: eterno retorno da poesia do mar, da vida de alguns instantes em apneia; alguns instantes que nos banham com uma infinidade estética, com obras de arte flutuantes.

\section{O corpo intensivo do mergulho: apneia para não sufocar}

É preciso dizer que, quando mergulhamos, cada descida não dura muito mais do que um minuto e isso quando se consegue administrar bem o ar e a água não está muito fria. Paradoxalmente, o curto minuto em que estamos submersos faz o tempo dilatar e também as referências de espaço se embaralham perigosamente. O único norte é o fôlego e, às vezes, o som das pulsações de nosso coração: pequenos fios que nos mantém atarraxados à condição de corpo humano.

Mas mergulhamos porque é possível estar sob outro regime de sensibilidade. Prendemos a respiração para não sermos sufocados pela nossa realidade humana. Se, em nossa vida de homens urbanos hegemônicos, vivemos sufocados pela poluição, paradoxalmente, encontramos uma bolha de respiro ao nos afundarmos em apneia na selva de esmeralda líquida: o mergulho é prática de arejamento. Claro que é frequente acharmos latinhas, tampas de garrafas, pedaços de sacola plástica. Também é evidente que recolhemos esses resíduos, pois é comum matarem aves e tartarugas-marinhas, que os comem por os confundirem com conchas e águas-vivas. Porém, ao mergulharmos, nos damos conta de que nossa realidade civilizada, urbana e terrena é apenas uma realidade e de que as terras fantásticas de Alice talvez devessem ser marinhas. Mergulhar é estar no caldo primordial, movente, indócil - e ao mesmo tempo, quieto, eterno em seu sutil trinado -, de onde surgiu a vida.

No breve minuto submerso quase asfixiamos e, contudo, tendo sentido a multiplicidade de vidas existentes neste outro mundo de nosso mundo, sempre emergimos menos engasgados com nossa realidade, voltamos capazes de respirar melhor. Dito de outro modo, mergulhamos porque lá somos acossados por sensações, tempos e vidas inumanas, distantes de nosso aparato afectivo ordinário. Na água, vivemos o paradoxo de sermos acolhidos por um território onde somos estrangeiros, um envolvimento perigoso, profundo. Então, o mergulho é um exercício de experimentação de novos fluxos afectivos, sensações insuspeitas, estrangeiras à sensibilidade dominante e ao organismo.

É que, ao mergulharmos, sempre queremos ficar mais, sempre levamos o fôlego até o último segundo, afrontando aquilo que pode o organismo, como se fosse possível encontrar um lar em meio àquele mundo hostil aos nossos órgãos. São tentativas desconfortáveis, insanas, mas irresistíveis. Tantas vezes também, quando afundamos mais, somos judiados por correntes de água muito fria. Ora, ao mergulharmos, não buscamos sensações de prazer, não desejamos o afável. O corpo ali se dispõe a um novo campo de sensibilidade, extravasa o bom senso de manter-se isento dos medos e é navegado por inumeráveis pequenas construções e desconstruções. Uma delas é a certeza de que só um pensar absolutamente teórico, abstrato e apartado da experiência do mundo poderia ter concebido um ideal de beleza caracterizado pela harmonia e pela simetria, pois no mar, lá onde a vida surgiu, nada tem esta aparência 
imediatamente confortável e agradável. O conceito de belo foi criado num aquário, não na selva marinha.

Portanto, devemos considerar que também faz parte de nosso organismo toda maneira de sentir e pensar adaptada para viver no mundo dos homens normais, sadios e sensatos; a prática do mergulho coloca em risco esse campo organísmico. Ademais, o mergulho tomado como ação livre, liberta da necessidade de sobrevivência e do cumprimento de resultados, despregada ainda da performance narcísica das praias badaladas, é também uma prática experimental, produtora deste corpo que, imerso no mundo marinho, deflui afectos de diversas ordens. Porém, é importante precisar que o $\mathrm{CsO}$ intensivo do mergulho não é o corpo do mergulhador transformado, mas é um corpo que transforma o mergulhador, porque o envolve, o implica num campo afectivo, numa realidade sensacional deslocante e inventiva. $\mathrm{O} \mathrm{CsO}$ intensivo do mergulho é um agenciamento, em que nosso corpo é apenas um dentre todos os campos de sensibilidade que circulam e se articulam desvairadamente.

"Os afectos são precisamente estes devires não humanos do homem [...]" (DELEUZE; GUATTARI, 1992, p.220) Os afectos não são sentimentos vividos: são a vida que se desenrola no vivido, são o que há de vívido no vivido. A função do mergulhador é se deixar percorrer pelos afectos do mar. Assim, todo corpo intensivo é feito de campos sensíveis inventivos, cuja possibilidade oferecida é a de "ter sempre um pequeno pedaço de uma nova terra" (DELEUZE; GUATTARI, 1996, p.24). E o mergulho é o exercício de experimentar ciclicamente entre descidas e subidas, apneias e inspirações - um CsO povoado de blocos de afectos inumanos, deslocados de nossa sensibilidade assentada. No mergulho passam linhas afectivas que disjuntam a sensibilidade afeita apenas a sentimentos razoáveis, hostis a paradoxos. Tanto é que, no mar, como vimos, enfrentamos o tempo todo o limite da falta de oxigênio, as ondas de água fria, as criaturas e os medos da nossa própria profundidade, para podermos constituir um corpo capaz de sustentar sentidos paradoxais; corpo o qual secreta animais de seu próprio mar, enquanto se conecta com seres e paisagens fantásticos do mundo marinho. Com efeito, vimos que os afectos do $\mathrm{CsO}$ do mergulho são ideias desrazoadas, tão potentes quanto mais possam compor novos blocos afectivos, conservando simultaneidades alógicas, isto é, conservando a intensidade.

Portanto, o corpo intensivo é aquele que, a partir da relação experimental entre corpos, se faz capaz de expressar afectos cheios de simultaneidades e vivacidades insuspeitas. O CsO do mergulho permite que a vida do corpo não seja demasiadamente concreta, mas marmoreada, molhada não apenas pelos peixes coloridos que vemos, mas também por afectos estrangeiros. O corpo intensivo é um corpo que se 'artificializa' e, assim, multiplica a realidade, enquanto prolifera campos de sensibilidade novos.

Aprendemos mergulhando que o corpo intensivo é este que, paradoxalmente, mergulha numa superfície, aprofunda-se ao perder o fundo, torna evidente a secreta multiplicidade que constitui o mundo. Voltar do fundo do mar é fazer emergir um corpo feito de um novo campo de sensibilidade.

\section{AN UNDERWATER CARTOGRAPHY TO THINK ABOUT THE INTENSIVE BODY PRODUCTION}

\section{Abstract}

This work intends to present a cartography of the practice of free diving and, based on the concept of body without organs from the works of Deleuze and Guattari, extract elements that allow to reflect on the production of an intensive body, distinct from the organic body. We start from the notion that the body without organs is the body of the circulating affections of an encounter between bodies. We intend to contribute to the reflections about the body, mak- 
ing a list of affections of the free diving practice at sea, elaborating the notion that an intensive body is constructed from experiments capable of constitute new fields of sensitivity.

Key words: Cartography. Diving. Body. Sensitivity.

\section{UNA CARTOGRAFÍA SUMERGIDA PARA PENSAR LA PRODUCCIÓN DEL CUERPO INTENSIVO}

\section{Resumen}

Este trabajo pretende presentar una cartografía sobre la práctica de buceo libre y, tomando como base la concepción de cuerpo sin órganos de las obras de Deleuze y Guattari, procuramos extraer elementos que permitan reflexionar sobre la producción de un cuerpo activo, distinto del cuerpo orgánico. Partimos de la idea de que el cuerpo sin órganos es el cuerpo de los afectos circulantes en un encuentro entre cuerpos. Tenemos la intención de contribuir para las reflexiones sobre el cuerpo, elaborando una lista de aficionados a la práctica de buceo libre en el mar, elaborando la idea de que un cuerpo activo se construye a partir de experiencias capaces de formar nuevos campos de sensibilidad.

Palabras clave: Cartografía. Buceo. Cuerpo. Sensibilidad.

\section{Referências}

ALVAREZ, J.; PASSOS, E. Cartografar é habitar um território existencial. In: PASSOS, E.; KASTRUP, V.; ESCÓSSIA, L. (Org.). Pistas do método da cartografia: pesquisa intervenção e produção de subjetividade. Porto Alegre: Sulina, 2010.

AMADOR, F.; FONSECA, T. M. Da intuição como método filosófico à cartografia como método de pesquisa: considerações sobre o exercício cognitivo do cartógrafo. Arquivos Brasileiros de Psicologia, Rio de Janeiro, v. 61, n. 1, abr. 2009.

ARTAUD, A. O teatro e seu duplo. São Paulo: Martins Fontes, 2006.

DELEUZE, G. Crítica e clínica. São Paulo: Editora 34, 1997.

DELEUZE, G. Espinosa: filosofia prática. São Paulo: Escuta, 2002.

DELEUZE, G.; GUATTARI, F. O Anti -Édipo: capitalismo e esquizofrenia. São Paulo: Editora $34,2010$.

DELEUZE, G.; GUATTARI, F. Mil platôs: capitalismo e esquizofrenia. Rio de Janeiro: Editora 34,1996 . v.3.

DELEUZE, G.; GUATTARI, F. Mil platôs: capitalismo e esquizofrenia. São Paulo: Editora 34, 1997a. v.4.

DELEUZE, G.; GUATTARI, F. Mil platôs: capitalismo e esquizofrenia. São Paulo: Editora 34, 1997b. v.5.

DELEUZE, G.; GUATTARI, F. O que é a filosofia? Rio de Janeiro: Editora 34, 1992.

FOUCAULT, M. Microfísica do poder. Rio de Janeiro: Graal, 2000. 
KIRST, P. Conhecimento e cartografia: tempestade de possíveis. In: FONSECA, T. M.; KIRST, P. (Org.). Cartografias e devires: a construção do presente. Porto Alegre: Editora UFRGS, 2003.

ORLANDI, L. Corporeidades em minidesfile. In: FONSECA, T.M.; ENGELMAN, S. (Org.). Corpo arte e clínica. Porto Alegre: Editora UFRGS, 2004.

TSÉ, L. Tao Te King. Curitiba: Hemus, 2000.

Recebido em: 11/02/2017

Revisado em: 20/04/2017

Aprovado em: 20/04/2017

Endereço para correspondência:

fefoyo@yahoo.com.br

Fernando Yonezawa

Universidade Federal do Espirito Santo,

Campus de Goiabeiras

Av. Fernando Ferrari, 514 - Goiabeiras,

29075-910-Vitória - ES, Brasil 